\title{
INTERVENSI MENGUNYAH PERMEN KARET EFEKTIF MENCEGAH DAN MENURUNKAN DERAJAT MUKOSITIS ORAL PADA ANAK YANG MENJALANI KEMOTERAPI
}

\author{
Agnita Utami ${ }^{1}$, Allenidekania ${ }^{2}$, Happy Hayati $^{3}$ \\ ${ }^{1}$ Program Studi Ilmu Keperawatan STIKes Hang Tuah Pekanbaru \\ ${ }^{2.3}$ Departemen Keperawatan Anak, Fakultas Ilmu Keperawatan Universitas Indonesia, \\ Email: agnitautami@gmail.com
}

\begin{abstract}
Abstrak
Mukositis oral merupakan efek samping yang paling sering dialami anak yang menjalani kemoterapi. Mukositis menyebabkan gangguan fisiologis dan fungsional yang menurunkan kualitas hidup anak kanker. Mengunyah permen karet merupakan salah satu intervensi non farmakologis yang dapat dilakukan untuk mengatasi mukositis oral. Tujuan penelitian ini adalah melihat efektivitas mengunyah permen karet dalam menurunkan derajat mukositis oral. Penelitian ini melibatkan 40 orang pasien anak yang terbagi dalam dua kelompok yaitu kelompok intervensi dan kelompok kontrol Hasil analisis statistik menunjukkan mengunyah permen karet lebih efektif dibandingkan berkumur larutan chlorhexidine $(\mathrm{p}=0,008)$. Mengunyah permen karet dapat digunakan sebagai salah satu protokol perawatan mulut pada anak yang mendapatkan kemoterapi.
\end{abstract}

Kata kunci: kanker, kemoterapi, mukositis, mengunyah permen karet

\begin{abstract}
Oral mucositis is the most common side effect of a child undergoing chemotherapy. Mucositis causes physiological and functional disorders that decrease the quality of life of cancer children. Chewing gum is one of the nonpharmacological interventions that can be done to treat oral mucositis. The purpose of this study is to see the effectiveness of chewing rubber oermen in decreasing the degree of oral mucositis. The implementation of evidencebased nursing practice involved 40 pediatric patients divided into two groups were intervention and control groups. Statistical analysis showed chewing gum was more effective than gargling chlorhexidine solution $(p=0.008)$. Thus chewing gum solution can be used as one of the child care protocols that get chemotherapy
\end{abstract}

Keyword: cancer, chemotherapy, chewing gum, mucositis,

\section{PENDAHULUAN}

Kanker merupakan salah satu penyakit kronis yang dapat menyebabkan kematian pada anak. Kanker pada anak dapat disembuhkan apabila terdeteksi sejak dini serta menjalani pengobatan dan perawatan dengan baik. Kemajuan pengobatan kanker dalam beberapa dekade terakhir menyebabkan lebih dari $80 \%$ anak dengan kanker dapat bertahan hidup selama 5 tahun atau lebih. Namun, tingkat kelangsungan hidup bervariasi tergantung pada jenis kanker dan faktor lainnya (American Cancer Society, 2015). Kemoterapi merupakan model pengobatan 
Agnita Utami $^{1}$, Allenidekania ${ }^{2}$, Happy Hayati ${ }^{3}$,Intervensi Mengunyah Permen Karet Efektif Mencegah Dan Menurunkan Derajat Mukositis Oral Pada Anak Yang Menjalani Kemoterapi

untuk kanker sistemik. Pengobatan ini efektif untuk anak dengan kanker, terutama pada leukemia dan limfoma yang tidak dapat ditangani secara efektif dengan terapi radiasi dan pembedahan (Bowden \& Greenbergh, 2010; Marcdante, Kliegman, Jenson \& Behrman, 2014).

Meskipun kemoterapi menjadi pengobatan kanker yang efektif pada anak, kemoterapi juga dapat menimbulkan beberapa efek samping. Salah satu efek samping yang dapat terjadi karena pemberian kemoterapi adalah mukositis oral. Mukositis oral adalah peradangan pada mukosa mulut yang secara klinis ditandai dengan adanya eritematosa pada mukosa mulut yang kemudian dapat menjadi ulserasi. Mukositis oral disebabkan oleh rusak atau hancurnya sel epitel mukosa dan penekanan pertumbuhan sekunder akibat pengobatan antineoplastik seperti kemoterapi dan radioterapi (Martin \& Perez, 2014). Kejadian mukositis oral dilaporkan sekitar 20$40 \%$ pada pasien yang mendapatkan kemoterapi konvensional, sekitar 80\% terjadi pada pasien yang mendapatkan kemoterapi dosis tinggi, dan pada hampir semua pasien yang mendapatkan radiasi area kepala dan leher (Miranzadeh, Adib-Hajbaghery, Soleymanpoor, \& Ehsani, 2014)

Mukositis oral dapat menyebabkan banyak komplikasi yang mengganggu fungsi dan integritas rongga mulut, mulai dari kesulitan berbicara, kesulitan menelan, hingga rasa nyeri yang hebat, dan dapat menyebabkan infeksi sistemik yang mempengaruhi status fungsional dan kualitas hidup. Jenis agen kemoterapi yang digunakan, dosis tertentu, cara pemberian, frekuensi, dan apakah kemoterapi adalah diberikan sebagai monoterapi atau kombinasi dengan agen lain dan modalitas pengobatan secara signifikan mempengaruhi tingkat keparahan mukositis oral. Berbagai siklus kemoterapi dan paparan agen kemoterapi sebelumnya dapat meningkatkan risiko kejadian mukositis (Svanberg, 2010; Martin \& Perez, 2014). Beberapa metode telah diteliti untuk mencegah atau menangani mukositis oral pada anak yang mendapat kemoterapi antara lain penggunaan madu, larutan salin, terapi dingin (cryotherapy), ekstrak tanaman herbal, dan permen karet.

Penelitian yang dilakukan oleh Didem, Ayfer, dan Ferda (2014) tentang efek mengunyah permen karet terhadap mukositis oral pada anak yang menjalani kemoterapi membuktikan bahwa mengunyah permen karet efektif untuk mencegah dan menurunkan derajat keparahan mokusitis oral pada anak yang mendapat kemoterapi. Penelitian tentang efek mengunyah permen karet juga dilakukan oleh Eghbali, Taherkhanehi, Bagheri, dan Sadegi (2014). Penelitian tersebut menunjukkan bahwa stimulasi saliva akibat mengunyah permen karet dapat menurunkan 
derajat keparahan mukositis oral pada anak selama kemoterapi.

Penatalaksanaan mukositis oral Di RSPUN dr. Cipto Mangunkusomo yang biasa dilakukan adalah berupa dekontaminasi oral menggunakan chlorhexidine $0,2 \%$. Berdasarkan hasil observasi yang dilakukan terhadap anak yang menjalani kemoterapi di RSUPN dr. Cipto Mangunkusomo bahwa dari 5 orang pasien, 3 diantaranya tidak menggunakan chlorhexidine 0,2 \% yang diberikan untuk berkumur dikarenakan rasa yang tidak enak dan pedas. Beberapa hasil penelitian menunjukkan bahwa penggunaan chlorhexidine $0,2 \%$ tidak menunjukkan keefektifan dalam menurunkan derakat keparahan mukositis (Bardy et al., 2008; Shih et al, 2003). Sedangkan Haris et al (2008) menyebutkan bahwa chlorhexidine 0,2\% dan iodine tidak boleh diberikan dalam jangka waktu yang lama karena dapat mengganggu flora normal dimulut dan menyebabkan mulut kering serta mudah teriritasi.

Perawat sebagai tenaga kesehatan profesional memiliki peran dalam upaya mencegah dan menangani mukositis oral pada anak yang mendapat kemoterapi. Oleh karena itu, peneliti tertarik untuk menerapkan Evidence Based Nursing Practice (EBNP) mengunyah permen karet sebagai salah satu intervensi keperawatan untuk mencegah dan menangani mukositis oral pada anak yang mendapat kemoterapi. Tujuan dari penerapan
EBNP ini adalah untuk melihat efektivitas mengunyah permen karet dalam mencegah dan menurunkan derajat keparahan mukositis oral pada anak yang menjalani kemoterapi.

\section{METODE}

Penelitian ini dilakukan di ruang rawat anak RSUPN Cipto Mangunkusomo dengan jumlah responden 40 orang. Peneliti membagi responden menjadi dua kelompok, yaitu kelompok intervensi, mengunyah permen karet dan kelompok berkumur larutan chlorhexidine $0,2 \%$. Responden dalam penerapan penelitian ini adalah anak usia 6-18 tahun yang menjalani kemoterapi dengan efek mukotoksik tinggi. Derajat mukositis pada kedua kelompok diukur menggunakan sistem skoring WHO, pengukuran dilakukan sebanyak 2 kali, yaitu sebelum diberikan intervensi (pre test) setelah dilakukan intervensi (post test). Intervensi dilakukan selama 6 hari pada setiap responden. Intervensi mengunyah permen karet dilakukan 3 kali sehari, anak diminta mengunyah permen karet selama 10 menit, 1 jam sebelum dilakukan intervensi anak dipuasakan baik makanan maupun minuman. Sedangkan untuk intervensi berkumur larutan chlorhexidine 0,2 $\%$ dilakukan sesuai dengan instruksi dokter yaitu 3 kali sehari dan 1 jam sebelum dilakukan berkumur anak dipuasakan baik makanan maupun minuman. Post test dilakukan pada hari ke tujuh. Analisis data menggunakan analisis data univariat dan 
Agnita Utami $^{1}$, Allenidekania ${ }^{2}$, Happy Hayati ${ }^{3}$,Intervensi Mengunyah Permen Karet Efektif Mencegah Dan Menurunkan Derajat Mukositis Oral Pada Anak Yang Menjalani Kemoterapi

bivariat, yaitu menggunakan uji Dependent $T$

Test. Penelitian ini dilakukan selama 7

minggu.

\section{HASIL}

Tabel 1.

Proporsi Derajat Mukositis Sebelum dan Sesudah Intervensi Pada Kelompok Mengunyah Permen Karet dan Kelompok Berkumur Di RSUPN Cipto Mangunkusomo Maret-April $2017(N=40)$

\begin{tabular}{|c|c|c|c|c|}
\hline No & Pengukuran & $\begin{array}{c}\text { Derajat } \\
\text { Mukositis }\end{array}$ & $\begin{array}{c}\text { Kel. } \\
\text { Mengunyah } \\
\text { permen } \\
\text { karet }\end{array}$ & $\begin{array}{c}\text { Kel. } \\
\text { Berkumur } \\
\text { chlorhexidine } \\
0,2 \%\end{array}$ \\
\hline 1 & $\begin{array}{l}\text { Sebelum } \\
\text { Intervensi }\end{array}$ & $\begin{array}{c}\text { Normal } \\
\text { Derajat } 1 \\
\text { Derajat } 2 \\
\text { Derajat } 3 \\
\text { Derajat } 4\end{array}$ & $\begin{array}{l}5(25) \\
8(40) \\
7(35) \\
0(0) \\
0(0)\end{array}$ & $\begin{array}{c}11(55) \\
7(35) \\
1(5) \\
1(5)\end{array}$ \\
\hline 2 & $\begin{array}{c}\text { Setelah } \\
\text { intervensi }\end{array}$ & $\begin{array}{c}\text { Normal } \\
\text { Derajat } 1 \\
\text { Derajat } 2 \\
\text { Derajat } 3 \\
\text { Derajat } 4\end{array}$ & $\begin{array}{l}11(55) \\
7(35) \\
1(5) \\
1(5)\end{array}$ & $\begin{array}{c}10(50) \\
7(35) \\
3(15)\end{array}$ \\
\hline
\end{tabular}

Tabel 1 menunjukkan proporsi derajat mukositis pada kelompok mengunyah permen karet dan kelompok berkumur sebelum dan sesudah dilakukan intervensi. Pada kelompok mengunyah permen karet, sebelum dilakukan intervensi, paling banyak responden mengalami mukositis derajat 1 yaitu sebanyak 8 orang $(40 \%)$, sedangkan setelah dilakukan intevensi sebagian besar responden tidak mengalami mukositis yaitu sebanyak 11 orang
(55\%), dan tidak ada responden yang mengalami mukositis derajat 3 dan 4. Pada kelompok berkumur sebelum intervensi sebagian besar responden tidak mengalami mukositis yaitu sebanyak 11 orang (55\%), setelah dilakukan intervensi sebagian besar responden tidak mengalami mukositis (50\%), namun terdapat 3 orang responden yang mengalami mukositis derajat $3(15 \%)$. 
Tabel 2.

Perbedaan Proporsi Derajat Mukositis Sebelum dan Sesudah Intervensi Pada Kelompok Mengunyah Permen Karet dan Kelompok Berkumur Di RSUPN Cipto Mangunkusomo Maret-April $2017(N=40)$

\begin{tabular}{llllll}
\hline o & Kelompok & $\begin{array}{c}\text { Derajat } \\
\text { Mukositis }\end{array}$ & $\begin{array}{c}\text { Sebelum } \\
\text { Intervensi }\end{array}$ & $\begin{array}{c}\text { Sesudah } \\
\text { Intervensi }\end{array}$ & $\begin{array}{c}\text { P } \\
\text { value }\end{array}$ \\
\hline 1 & Mengunyah & Normal & $5(25)$ & $12(60)$ & 0,001 \\
& Permen & Derajat 1 & $8(40)$ & $8(40)$ & \\
& Karet & Derajat 2 & $7(35)$ & $0(0)$ & \\
& & Derajat 3 & $0(0)$ & $0(0)$ & \\
& & & & & \\
\hline 2 & Berkumur & Normal & $11(55)$ & $10(50)$ & 0,782 \\
& & Derajat 1 & $7(35)$ & $7(35)$ & \\
& & Derajat 2 & $1(5)$ & $3(15)$ & \\
& & Derajat 3 & $1(5)$ & & \\
\hline
\end{tabular}

Berdasarkan tabel 2 diatas dapat dilihat bahwa derajat mukositis oral pada kelompok mengunyah permen karet sebelum dilakukan intervensi paling banyak mengalami mukositis oral derajat 1, yaitu sebanyak 8 orang (40\%), sedangkan sesudah intervensi sebagian besar tidak mengalami mukositis oral $(60 \%)$. Nilai $p$ pada kelompok mengunyah permen karet adalah $0,001(<0,05)$ yang berarti bahwa ada perbedaan derajat mukositis oral sebelum dan sesudah dilakukan intervensi mengunyah Tabel 3.

Perbedaan Proporsi Derajat Mukositis Sebelum dan Sesudah Intervensi Antara Kelompok Mengunyah Permen Karet dan Kelompok Berkumur Di RSUPN Cipto Mangunkusomo Maret-April 2017 (N=40)

\begin{tabular}{lcccccc}
\hline \multirow{2}{*}{ No } & \multirow{2}{*}{ Pengukuran } & Kelompok & \multicolumn{2}{c}{ Perubahan Derajat Mukositis } & \multirow{2}{*}{ P value } \\
\cline { 3 - 5 } & & Turun & Tetap & Naik & \\
\hline \multirow{2}{*}{1} & Setelah Intervensi & Berkumur & 5 & 10 & 5 & \\
\cline { 3 - 5 } & & $\begin{array}{c}\text { Mengunyah } \\
\text { permen karet }\end{array}$ & 12 & 8 & 0 & 0,008 \\
\hline
\end{tabular}

Berdasarkan tabel 3 dapat dilihat proporsi perbedaan perubahan derajat mukositis setelah dilakukan intervensi pada permen karet. Pada kelompok berkumur sebagian besar tidak mengalami mukositis oral sebelum dilakukan intervensi, yaitu sebanyak 11 orang $(55 \%)$, sedangkan setelah dilakukan intervensi sebagian besar juga tidak mengalami mukositis oral (50\%), dan terdapat 3 orang (15\%) yang mengalami mukositis derajat 2. Nilai p untuk kelompok berkumur adalah $0,782(>0,05)$ yang berarti bahwa tidak terdapat perbedaan derajat mukositis sebelum dan sesudah intervensi berkumur. 
Agnita Utami ${ }^{1}$, Allenidekania ${ }^{2}$, Happy Hayati ${ }^{3}$,Intervensi Mengunyah Permen Karet Efektif Mencegah Dan Menurunkan Derajat Mukositis Oral Pada Anak Yang Menjalani Kemoterapi

mengalami penurunan derajat mukosiitis sedangkan dari kelompok berkumur hanya 5 orang yang mengalami penurunan derajat mukositis. Sebanyak 8 orang dari kelompok mengunyah permen karet yang mengalami derajat mukositis tetap, dan sebanyak 10 orang dari kelompok berkumur mengalami derajat mukositis tetap. Responden yang mengalami peningkatan derajat mukositis yaitu sebanyak 5 orang dan seluruhnya berasal dari kelompok berkumur. Nilai p yang diperoleh berdasarkan uji statistik adalah $0,008(<0,05)$ yang berarti intervensi mengunyah permen karet efektif dalam menurunkan derajat mukositis oral pada anak yang mendapat kemoterapi

\section{PEMBAHASAN}

Berdasarkan hasil pengukuran awal derajat mukositis pada kelompok mengunyah permen karet dan kelompok berkumur didapatkan bahwa terdapat beberapa anak dari kedua kelompok yang sudah mengalami mukositis. Hal ini disebabkan oleh anak telah mendapat kemoterapi satu sampai dua minggu sebelumnya, dan anak mendapatkan agen kemoterapi dengan potensi mukositis tinggi seperti 5-fluorouracil dan methotrexate. Menurut Niscola et al (2007) Agen kemoterapi dengan potensi mukotoksik tinggi seperti etoposide, 5-fluorouracil, dan methotrexate diberikan untuk pengobatan kanker darah seperti ALL, AML, Limfoma non-Hodgkin's dan Limfoma Hodgkin. Untuk agen kemoterapi cisplatine digunakan sebagai terapi pada pasien-pasien osteosarkoma. Sebagian besar agen kemoterapi dapat mencapai mukosa melalui aliran darah, namun methotrexate dapat ditemukan pada kelenjar dan cairan saliva sehingga dapat merusak sel epitel mukosa secara langsung (direct mucosatoxicity).

Beberapa upaya yang pernah diteliti terkait pencegahan dan penanganan mukositis oral, antara lain adalah penggunaan cryotherapy (terapi dingin), ekstrak tanaman herbal, madu, larutan salin, dan permen karet. Pemberian terapi dingin (cryotherapy) dengan meletakkan es batu atau air es selama 5 menit sebelum sampai dengan 5 menit sesudah pemberian kemoterapi dapat menurunkan derajat keparahan mukositis oral. Namun, penggunaan terapi dingin memerlukan kriteria tertentu, yaitu anak tidak memiliki riwayat gigi sensitif karena dapat menimbulkan nyeri jika diletakkan es di mulut ( Heydari, Sharifi, \& Salek, 2012; Kakoei, Ghassemi, \& Nakhae, 2013). Penelitian lain yang dilakukan oleh Saldanha dan Almeida (2014) menunjukkan hasil bahwa berkumur dengan menggunakan larutan salin dapat mengurangi derajat keparahan mukositis oral yang disebabkan oleh terapi. Hal ini disebabkan karena larutan salin $(\mathrm{NaCl}$ 0,9\%) merupakan larutan isotonik yang aman, toksisitas rendah, tidak menyebabkan iritasi, membantu proses granulasi jaringan sehingga mempercepat 
penyembuhan. Selain itu, Nurhidayah (2014) telah melakukan penelitian terkait penggunaan madu untuk perawatan mulut pada pasien anak yang memperoleh kemoterapi. Hasil penelitian menunjukkan terjadi penurunan skor mukositis pada anak yang dilakukan perawatan mulut menggunakan larutan madu.

Penggunaan permen karet merupakan intervensi non farmakologis yang sudah ditemukan sejak tahun 1990 dan dikembangkan sampai sekarang (Didem, Ayfer, dan Ferda, 2014). Di Indonesia sendiri, penelitian tentang efektivitas mengunyah permen karet terhadap kejadian mukositis oral telah dilakukan oleh Utami (2016). Dalam penelitiannya Utami (2016) membandingkan efektivitas intervensi mengunyah permen karet dengan berkumur larutan salin. Permen karet yang digunakan adalah permen karet yang mengandung xylitol. Hasil penelitian menunjukkan bahwa mengunyah permen karet lebih efektif menurunkan skor mukositis oral dibandingkan dengan berkumur larutan salin. Penggunaan permen karet sebagai intervensi keperawatan tidak menyebabkan trauma dan nyeri pada anak. Berdasarkan hasil pengamatan saat dilakukan penerapan intervensi mengunyah permen karet, pasien lebih tertarik dan senang ketika diberi permen karet sebagai terapi untuk mengatasi mukositis oral dibandingkan dengan berkumur menggunakan chlorhexidine.
Dalam penelitian ini penelitian menggunakan jenis permen karet yang mengandung xylitol. Xylitol merupakan jenis gula alami yang berbeda dari gula biasa dan telah diteliti dapat mencegah caries gigi. Xylitol ditemukan secara alami dalam buah, sayuran, dan tanaman berkayu keras yang disebut birch (Nayak, Nayak. \& Khandelwal, 2014). Selanjutnya, Llop, Jimeno, Acien dan Dalmau (2010) dalam penelitiannya menyebutkan bahwa mengunyah permen karet yang mengandung xylitol dapat meningkatkan jumlah saliva dan $\mathrm{pH}$ saliva, serta mengurangi kandungan mutan Streptococus pada saliva. Permen karet yang tidak mengandung gula seperti xylitol dapat menurunkan angka Streptococus pada saliva, hal ini terjadi akibat efek antibacteria yang dimiliki xylitol sehingga dapat mengurangi terjadinya caries gigi (Burt, 2006; Aksoy, Duran, \& Koksal, 2005; Makinen, 2005).

Intervensi mengunyah permen karet pada anak yang mendapat kemoterapi memperoleh hasil bahwa terjadi penurunan derajat mukositis pada kedua kelompok intervensi, namun penurunan derajat mukositis lebih banyak terjadi pada kelompok mengunyah permen karet. Hasil penelitian ini sejalan dengan penelitian yang dilakukan oleh Didem, Ayfer, dan Ferda (2014) yang menyatakan bahwa terjadi penurunan derajat keparahan mukositis oral yang signifikan pada kelompok mengunyah permen karet dibanding 
Agnita Utami $^{1}$, Allenidekania ${ }^{2}$, Happy Hayati ${ }^{3}$,Intervensi Mengunyah Permen Karet Efektif Mencegah Dan Menurunkan Derajat Mukositis Oral Pada Anak Yang Menjalani Kemoterapi

kelompok kontrol. Dalam penelitiannya Didem, Ayfer, dan Ferda (2014) menyatakan penurunan derajat mukositis oral ini disebabkan oleh adanya peningkatan produksi dan $\mathrm{pH}$ saliva selama mengunyah permen karet.

Penelitian lain yang dilakukan Eghbali, Taherkhanehi, Bagheri, dan Sadegi (2014) menunjukkan bahwa stimulasi saliva akibat mengunyah permen karet dapat menurunkan derajat keparahan mukositis oral pada anak selama kemoterapi. Peningkatan produksi saliva merupakan hasil dari proses mastikasi dan rasa permen karet. Dalam keadaan tidak terstimulasi, saliva yang dikeluarkan sekitar $0,4 \mathrm{ml} / \mathrm{menit}$ pada individu yang sehat, dan jumlah saliva yang dikeluarkan dapat meningkat 10-12 kali lipat bila disertai dengan mengunyah permen karet. Peningkatan produksi saliva terjadi setelah 5-7 menit mengunyah permen karet karena sebagian besar komponen permen karet telah terurai di dalam mulut (Dodd, 2004; Llop et al., 2010).

Pada kelompok kontrol, peneliti memberikan intervensi berkumur menggunakan chlohexidine. Berdasarkan hasil evaluasi, penggunaan larutan chlorhexidine untuk berkumur juga dapat menurunkan derajat mukositis oral, namun jika dibandingkan dengan mengunyah permen karet angka penurunan derajat mukositis lebih banyak pada kelompok mengunyah permen karet. Chlorhexidine merupakan agen antimikrobial yang paling banyak digunakan dalam manajemen mukositis oral. Berkumur chlorhexidine dengan konsentrasi 0,12-0,2 \% dapat menjaga kebersihan mulut dan menurunkan inflamasi pada mukosa oral (Naidu et al., 2004). Namun, beberapa hasil penelitian lain menunjukkan bahwa penggunaan chlorhexidine $0,2 \%$ tidak menunjukkan keefektifan dalam menurunkan derajat keparahan mukositis (Bardy et al., 2008; Shih et al, 2003). Sedangkan Haris et al (2008) menyebutkan bahwa chlorhexidine 0,2 $\%$ dan iodine tidak boleh diberikan dalam jangka waktu yang lama karena dapat mengganggu flora normal dimulut dan menyebabkan mulut kering serta mudah teriritasi. Hal ini sesuai dengan hasil wawancara dan observasi yang dilakukan banyak anak yang menolak berkumur dengan chlorhexidine karena tidak suka dengan rasa dan sensasi (pedas) yang dirasakan akibat berkumur. Selain itu, peneliti juga tidak mengontrol responden saat berkumur, sehingga memungkinkan responden berkumur tidak sesuai dengan waktu yang telah ditetapkan. Hal ini dapat menjadi salah satu faktor penurunan derajat mukositis pada anak kelompok berkumur tidak signifikan. Bahkan ada beberapa anak dari kelompok berkumur yang mengalami peningkatan derajat mukositis.. 


\section{SIMPULAN}

Hasil penelitian menunjukkan bahwa terdapat perbedaan derajat mukositis oral sebelum dan sesudah dilakukan intervensi pada kelompok mengunyah permen karet. Intervensi mengunyah permen karet lebih efektif mencegah dan menurunkan derajat mukositis oral pada anak yang menjalani kemoterapi.

\section{DAFTAR PUSTAKA}

Aksoy, A., Duran, N., \& Koksal, F. (2006). In vitro and in vivo antimicrobial effects of mastic

chewing gum against Streptococcus mutans and mutans streptococci. Arch Oral Biol, 51 (6), 476-81.

Bardy, J., Slevin, N., Male, K.L., \& Mollasiotis, A. (2008). A systematic review of honey uses and its potential value within oncology care. Journal of Clinical Nursing, 17(1), 2604-2623.

Burt, B.A. (2006). The use of sorbitol and xylitol sweetened chewing gum in caries control. JADA, 137, 190-6.

Didem, A., Ayfer, E., \& Ferda, O.A. (2014). The effect of chewing gum on oral mucositis in children receiving chemotherapy. Health Science Journal, 8(3), 373-382.

Dodd, M.J. (2004). The pathogenesis and characteristic of oral mucositis associated with cancer therapy. Oncology Nursing Forum, 31(4), 5-12.

Eghbali, A., Taherkhanci, B., Bagheri, B., \& Sadeghi, S.B. (2014). Effect of chewing gum on oral mucositis in children undergoing chemotherapy: A randomized controlled study. Iranian Journal of Pediatric Hematology Oncology, 16 (1).

Gandemer, V., et al. (2007). Multicentre randomized trial of chewing gum for preventing oral mucositis in children receiving chemotherapy. $J$ Pediatr Hematol Oncol, 29 (2), 86-94.

Harris, J.D., Eilers, J., Harriman, A., Cashavelly, B., \& Maxwell, C. (2008). Putting evidence into practice: Evidence based intervention for management of oral mucositis. Clinical Journal of Oncology Nursing, 12(1), 141-147

Heydari, A., Sharifi, H., \& Salek, R. (2012). Effect of oral chryotherapy on combination chemotherapy-induced oral mucositis: A randomized clinical trial. Middle East Journal of Cancer, 3(2 \& 3), 55-64

Kakoei, S., Ghassemi, A., \& Nakhaee, N. (2013). Effect of cryotherapy on oral mucositis in patients with head and neck cancers receiving radiotherapy. International Journal of Radiation Research, 11(2), 117-120.

Kaushal, B., Narendra, D., \& Smitha. (2013). A comparative study between relaxation technique and aerobic exercise in fatigue during chemotherapy in acute lymphoblastic leukemia in children. Indian Journal of Physiotherapy \& Ocupational Therapy, 7(3), 140-146. doi:10.5958/j.0973-5674.7.3.081.

Lalla, R.V., Bowen, J., Barasch, A., Elting, L., Epstein, J., Keefe, D.M., et al. (2014). MASCC/ISOO clinical practice guidelines for the management of mucositis secondary to cancer therapy. Cancer, 120(10), 1453-1461.

Llop, M.R., Jimeno, F.G., Acien, R,M., \& Dalmau, L.J.B. (2010). Effect of xylitol chewing gum on salivary flow rate, ph, buffering capacity and presence of Streptococcus mutans in saliva. European Journal of Paediatric Dentistry, 11(1), 9-14.

Mäkinen, K.K. (2005). Six-month polyol chewing-gum programme in kindergarten-age children: a feasibility study focusing on mutans streptococci and dental plaque. Int Dent $J$, 55(2), 81-8.

Martin, C. A., \& Perez, M.G.S. (2014). Prevention and treatment of oral mucositis 
Agnita Utami ${ }^{1}$, Allenidekania ${ }^{2}$, Happy Hayati ${ }^{3}$,Intervensi Mengunyah Permen Karet Efektif Mencegah Dan Menurunkan Derajat Mukositis Oral Pada Anak Yang Menjalani Kemoterapi

in patients receiving chemotherapy. $J$ Clin

Exp Dent, 6(1), e74-80. doi: $10.4317 /$ jced.51313

Miranzadeh, S., Adib-Hajbaghery, M., Soleymanpoor, L., \& Ehsani, M. (2014). Effect of adding the herb Achiella millefolium on mouthwash on chemotherapy induced oral mucositis in cancer patients: A double-blind randomized controlled trial. European Journal of Oncology Nursing, 1-7. doi: 10.1016/j.ejon.2014.10.019

Naidu, et al. (2004). Chemotherapy-induced and/or radiation therapy-induced oral mucositis - complicating the treatment of cancer. Neoplasia, 6(5), 423-431.

Nayak, P.A., Nayak, U.A., \& Khandelwal, V. (2014). The effect of xylitol on dental caries oral flora. Clinical, Cosmetic and Investigational Dentistry, ,6, 89-94

Nurhidayah, I. (2011). Pengaruh pemberian madu dalam tindakan keperawatan oral care terhadap mukositis akibat kemoterapi pada anak di RSUPN DR. Cipto Mangunkusumo Jakarta (Tesis tidak dipublikasikan). Universitas Indonesia, Jakarta.
Qutob, A.F., Gue, S., Revesz, T., Logan, R.M., \& Keefe, D. ( 2013). Preventing of oral mucositis in children receiving cancer therapy: A systematic review and evidence based analysis. Oral Oncology, 49, 102-107

Saldanha, S.P., \& Almeida, V.D. (2014). A comparative study to asses the effectiveness of turmeric mouth wash versus saline mouth wash on Treatment Induced Oral Mucositis (TIOM) in a selected hospital at Mangalore. J Clinic Res Bioeth, 5(6). doi: 10.4172/21559627.1000200.

Shih, A., Miaskowski, C., Dodd, M.J., Stotts, M.A., \& MacPhail, D. (2003). Mechanism for radiation-induced oral mucositis and the consequence. Cancer Nursing, 26, 222-229.

Utami, K.C. (2016). Perbandingan efektivitas intervensi mengunyah permen karet dan berkumur larutan salin terhadap kejadian mukositis oral pada anak kanker yang mendapat kemoterapi (Tesis tidak dipublikasikan). Universitas Indonesia: Jakarta 